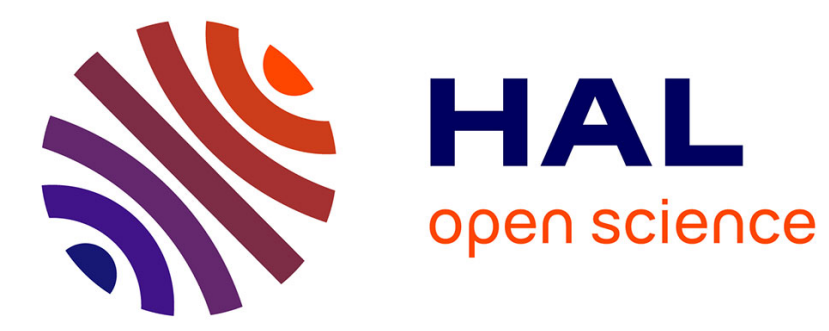

\title{
Applications of an Integrated XRF-XRD Spectrometer
}

R. Yellepeddi, A. Bapst, D. Bonvin

\section{To cite this version:}

R. Yellepeddi, A. Bapst, D. Bonvin. Applications of an Integrated XRF-XRD Spectrometer. Journal de Physique IV Proceedings, 1996, 06 (C4), pp.C4-781-C4-788. 10.1051/jp4:1996476 . jpa-00254359

\section{HAL Id: jpa-00254359 https://hal.science/jpa-00254359}

Submitted on 1 Jan 1996

HAL is a multi-disciplinary open access archive for the deposit and dissemination of scientific research documents, whether they are published or not. The documents may come from teaching and research institutions in France or abroad, or from public or private research centers.
L'archive ouverte pluridisciplinaire HAL, est destinée au dépôt et à la diffusion de documents scientifiques de niveau recherche, publiés ou non, émanant des établissements d'enseignement et de recherche français ou étrangers, des laboratoires publics ou privés. 
JOURNAL DE PHYSIQUE IV

Colloque C4, supplément au Journal de Physique III, Volume 6, juillet 1996

\section{Applications of an Integrated XRF-XRD Spectrometer}

R. Yellepeddi, A. Bapst and D. Bonvin

ARL, En Vallaire, 1024 Ecublens, Switzerland

\section{ABSTRACT}

An $X$-ray spectrometer which effectively integrates $X$-ray fluorescence and $X$-ray diffraction in a single instrument has been developed. The instrument uses same $X$-ray excitation, sample position, vacuum tank and control systems for both XRF and XRD measurements. It is shown that flexible elemental analysis together with specific phase/compound analysis can be accomplished in a quantitative way using such an instrument. Various applications in industrial process and quality control are illustrated.

\section{INTRODUCTION}

X-ray fluorescence (XRF) allows determination of elemental concentration in samples of various forms and nature. The main advantages over other analytical techniques lie in its speed, high stability and precision, wide dynamic range (ppm to $100 \%$ ) and generally easy sample preparation. Its use for the routine analysis of cement and building materials, ferrous and non-ferrous metals and alloys, geological samples and other oxides is well established.

On the other hand, X-ray diffraction (XRD) permits analysis of the phases or compounds found in the samples. It is more often used as a qualitative tool in central or research laboratories, rather than for quantitative determination for process control.

Combining both techniques for an analysis on the same sample is interesting because it will help identify the constituent elements present in the sample and how these elements are chemically bound together to form compounds.

\section{INTEGRATING AN XRD SYSTEM}

An innovative XRD channel has been designed. Its originality is that it is integrated inside an ARL $8600 X$-ray fluorescence spectrometer without compromising the XRF performance. It can therefore be configured with sequential and simultaneous XRF devices for rapid and flexible elemental/oxide analysis and with an XRD system for specific phase/mineral analysis. The integrated system comprises: (a) a polychromatic $X-$ ray source (b) a mounting means for mounting the sample so that it is illuminated with $X$ rays (c) one or more fluorescence channels able to select $X$-rays of paricular wavelenth and energy and having means for detecting said selected X-rays, (d) a diffraction system able to select a characteristic X-ray wavelength of said souce following diffraction of the $X$-rays by the sample and having a means for detecting said characteristic $X$-rays and ( $e$ ) an actuating means for controlling arcuate movement of the diffraction system relative to the sample so as to detect the $\mathrm{X}$-rays leaving the sample at different diffraction angles.

The XRD system has (a) very high sensitivity owing to the closely coupled diffraction optics (b) high reliability thanks to the optical encoder technology that drives the XRD and (c) very high stability (repeatability) owing to the vacuum environment 
among other features. The wavelength used for diffraction can be chosen from different characteristic lines of the $X$-ray tube employed depending on the application. Fort example, at least four different wavelenths are available when a Rh target $\mathrm{X}$-ray tube is used.

\section{APPLICATIONS}

We present here typical applications in industrial process and quality control areas where flexible elemental/oxide and at the same time, specific phase/mineral analysis is required.

\subsection{Cement Industry}

Wavelength Dispersive X-ray fluorescence (WDXRF) has long been an established analytical method for elements/oxides in the cement industry. Rapid analysis of raw materials, raw meal, clinker and cement on a routine basis is frequently accomplished by a simultaneous XRF spectrometer - 8 to 10 fixed channels are used to measure all the major and minor oxides - $\mathrm{Na}_{2} \mathrm{O}, \mathrm{MgO}, \mathrm{Al}_{2} \mathrm{O}_{3}, \mathrm{SiO}_{2}, \mathrm{SO}_{3}, \mathrm{~K} 2 \mathrm{O}, \mathrm{CaO}$, $\mathrm{Fe}_{2} \mathrm{O}_{3}$, etc.- in less than 40 s per sample.

On-line and reliable analysis of free lime in clinkers is one of the most important process control requirements in any cement industry. Free lime in clinkers as different from the total $\mathrm{CaO}$ can be quantitatively determined in less than 100 s using the integrated XRD system. Typical accuracy of $0.1-0.15 \%$ is easily achieved in addition to the excellent reproducibility.

The limestone additions in cements, which is regulated according to the European pre standard ENV-1:1992, can be analysed as a function of carbon content by XRF. However this method has several limitations : the carbon measured by XRF is the total carbon content (limestone carbon + organic binding/grinding agents) and is subject to errors due to sample preparation or pollution of the surface. In contrast, measurement of the XRD peak is specifically associated with $\mathrm{CaCO}_{3}$ phase which can therefore be quantified independently of these constraints. However, a high sensitivity configuration is required in order to achieve good accuracy and reproducibility particularly in the $1-5 \%$ range of $\mathrm{CaCO}_{3}$.

Figure 1 shows the XRD scan on three cement samples containing different proportions of limestone as filler. Thanks to the high sensitivity,one can clearly identify the XRD peak due to $\mathrm{CaCO}_{3}$ around $0.249 \mathrm{~nm}$. These scans show the expected behaviour when limestone is added i.e. higher the limestone intensity, lower the intensity of clinker phases.

\subsection{Iron and Steel industry}

Starting from the raw materials (iron ores) through sinters to slags, iron and steel, XRF can be positioned in different areas of process and quality control in this industry. X-ray diffraction (XRD), on the other hand, can be used to identify and quantify specific mineral content which may be judged critical in a particular process. For example, differentiation of $\mathrm{FeO}, \mathrm{Fe}_{2} \mathrm{O}_{3}, \mathrm{Fe}_{3} \mathrm{O}_{4}$ and eventually $\mathrm{Fe}$ (metallic) can be useful to optimise the sintering process or rationalise the reduction operation. Performing this 
analysis together with the elements/oxides in an iron ore or sintered sample at the same time could prove very practical.

Figure 2 shows the calibration curves for $\mathrm{Fe}_{2} \mathrm{O}_{3}$ covering a wide concentration range. The analysis time used here is 100 s although integration times around 40 s can effectively be used owing to the high sensitivity of the XRD system. Typical accuracies of about $0.5 \%$ can be obtained.

\subsection{Aluminium industry}

Starting from the raw materials (bauxite, aluminium bearing minerals) through alumina to aluminium metal and its alloys, XRF can be positioned in different areas of process and quality control in this industry. X-ray diffraction (XRD), on the other hand, can be used, for example, to perform the electrolytic bath analysis in addition to any other off-line applications.

Figure 3 shows the XRD scans on three samples and the identification of different diffraction peaks. The insets in the figure show the zoomed part of the scan around $\mathrm{CaF}_{2}$ and chiolite. Figure 4 and 5 show, for example, the calibration curves for the excess $\mathrm{AlF}_{3}$ and total Calcium respectively.

Figure 6 shows the calibration curve obtained for $\alpha-\mathrm{Al}_{2} \mathrm{O}_{3}$ in a series of alumina samples using the same XRD system.

\subsection{Titanium Oxides}

Another application area where a combination of XRF and XRD analysis is very useful is related to the titanium oxides/minerals in different forms. For example Rutile and Anatase are two forms of $\mathrm{TiO}_{2}$ which can be quantified using the XRD system while the same instrument can be used to measure all the impurities by XRF.

Figure 7 shows the XRD scan on a sample containing Rutile and Anatase phases. Figure 8 shows the calibration curve for the Rutile part.

\section{CONCLUSIONS}

An integrated spectrometer combining the virtues of $X$-ray fluorescence and $X$-ray diffraction has been shown to be very useful in several production process and quality control laboratories. This two-dimensional approach for the characterization of inorganic polycrystalline materials using the same instrument can prove to be increasingly efficient in future. 
Figure 1: XRD goniometer scans on three cement samples with different concentrations of limestone addition. The inset in the figure shows the expanded part of the scan around calcite peak.

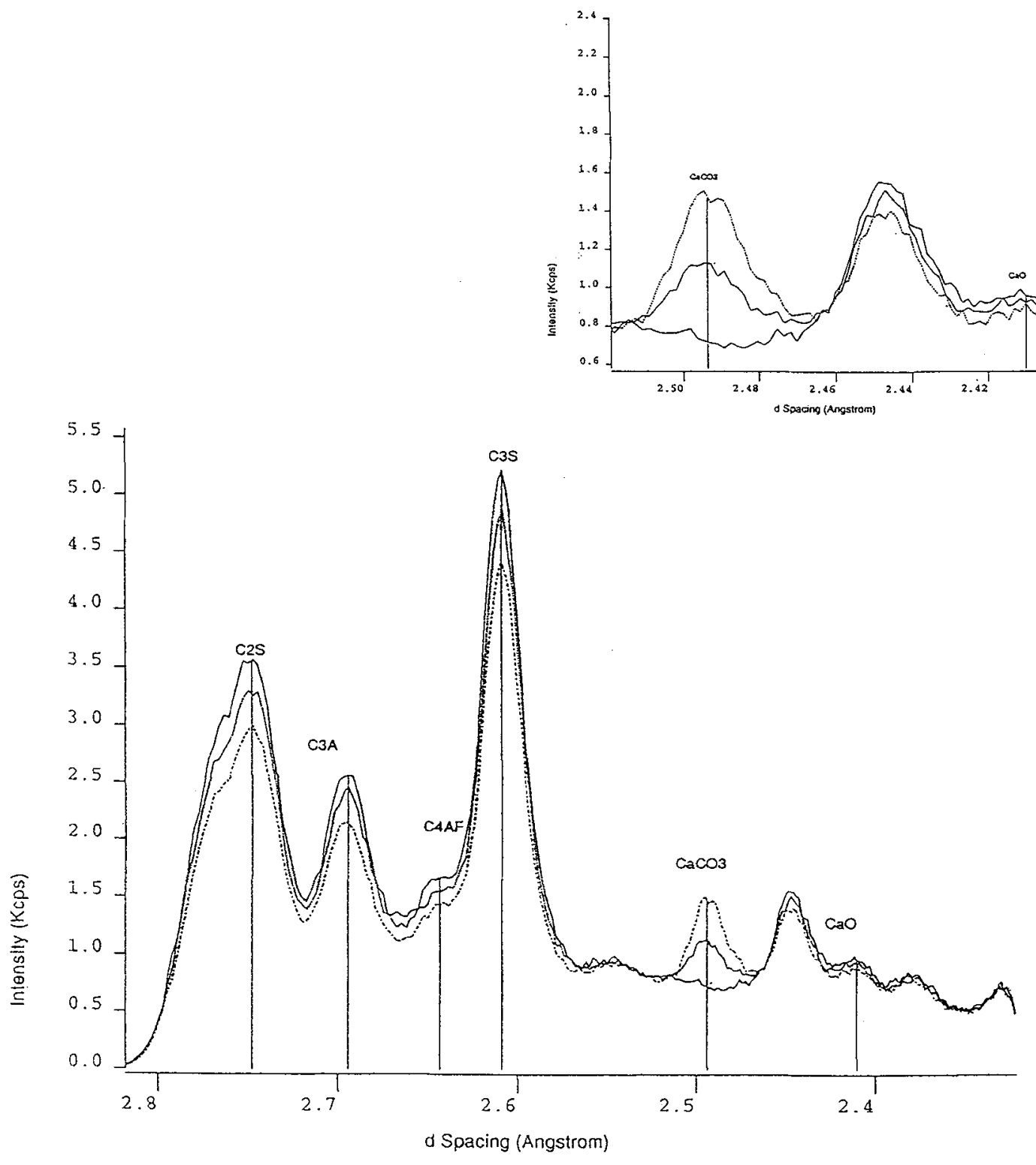


Figure 2: XRD Calibration Curve for $\mathrm{Fe}_{2} \mathrm{O}_{3}$ in Iron Ores

\section{Base Curve without Corrections}

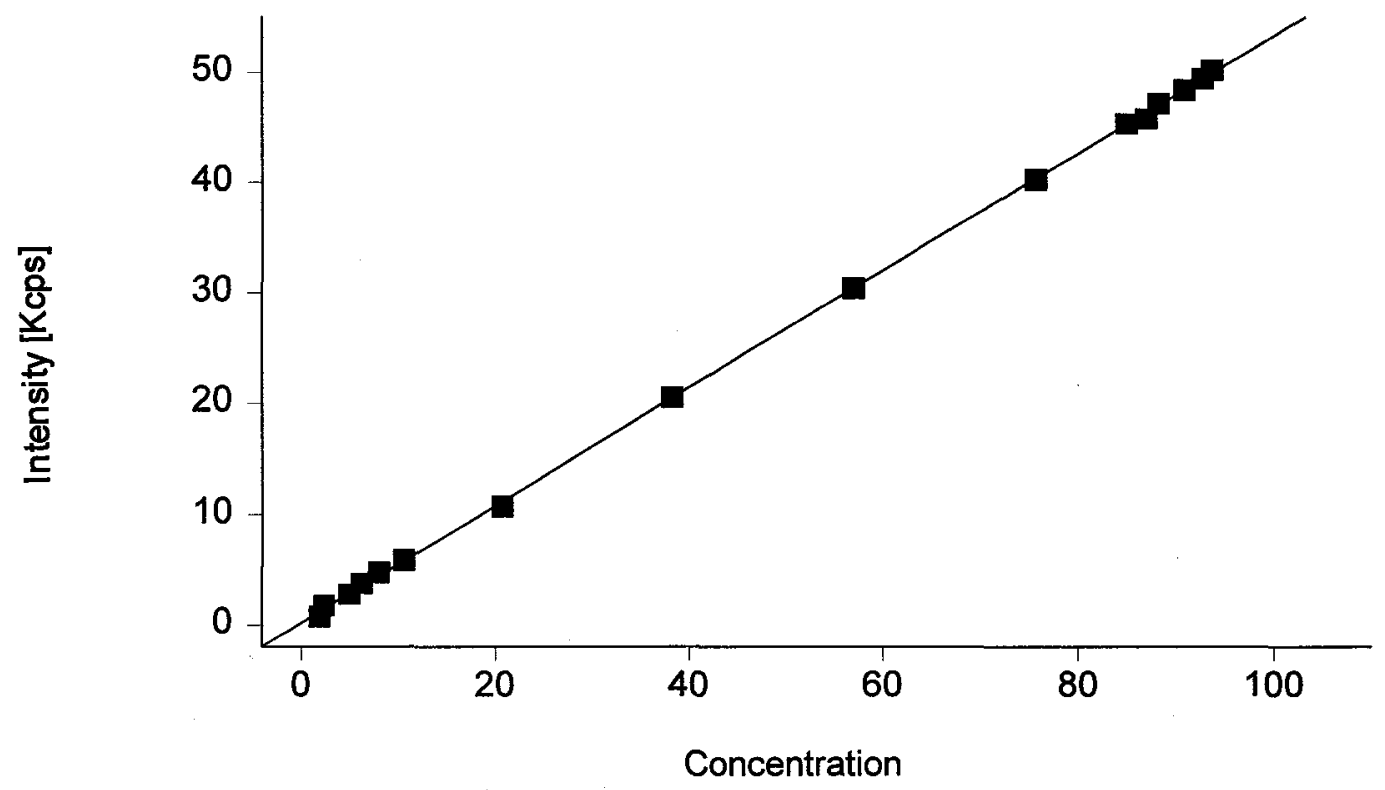

Figure 3: XRD scans on three samples (two bath electrolytes and one alumina) showing the diffraction peaks of $\mathrm{CaF}_{2}$, chiolite, cryolite and alpha- $\mathrm{Al}_{2} \mathrm{O}_{3}$. The insets show the expanded parts of the scan around $\mathrm{CaF}_{2}$ and chiolite.

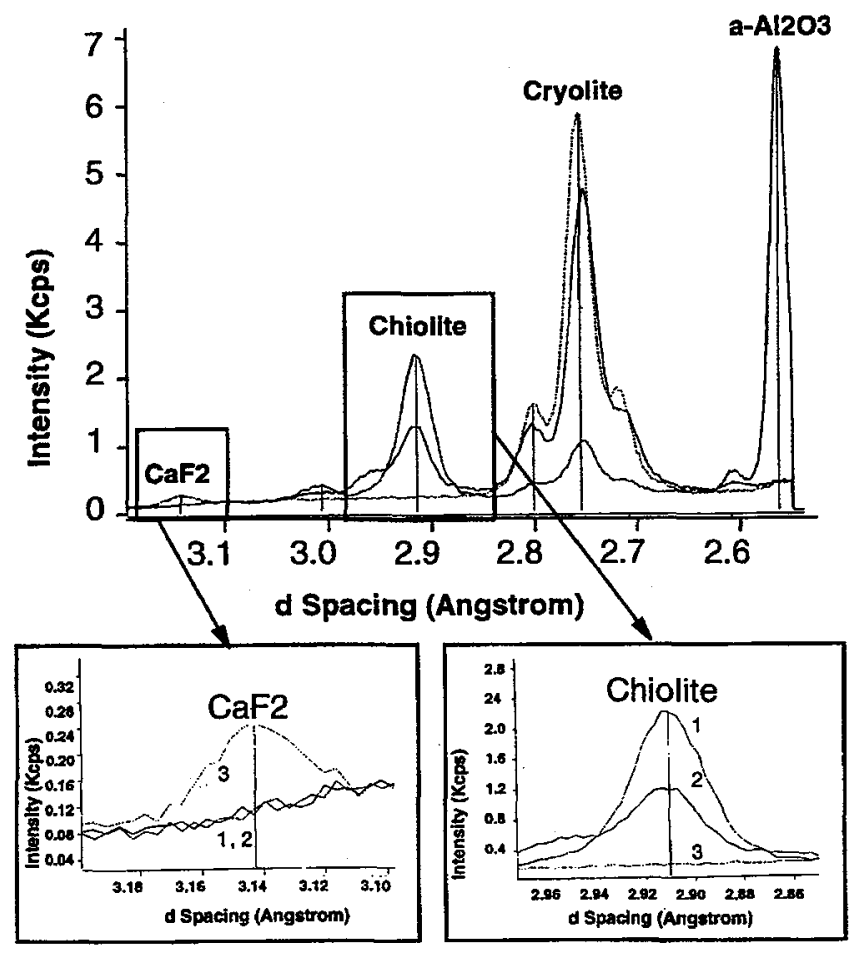


Figure 4: XRD calibration curve for the excess of $A F_{3}$ in a series of batch samples

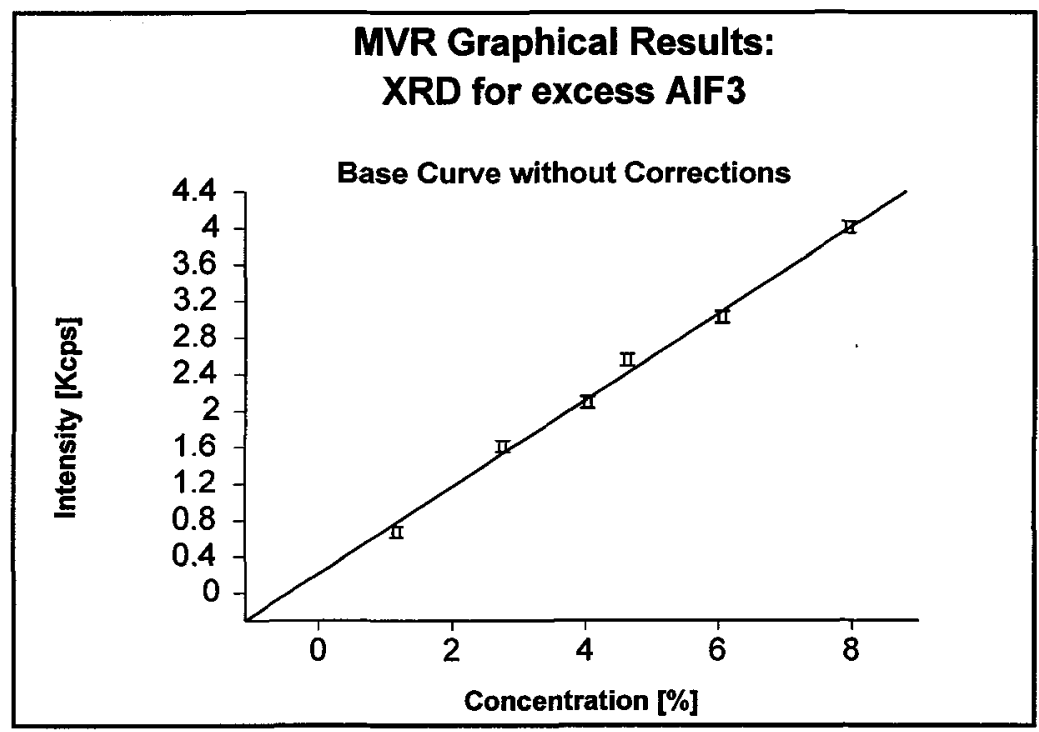

Figure 5: XRF calibration curve for the total calcium in the bath samples

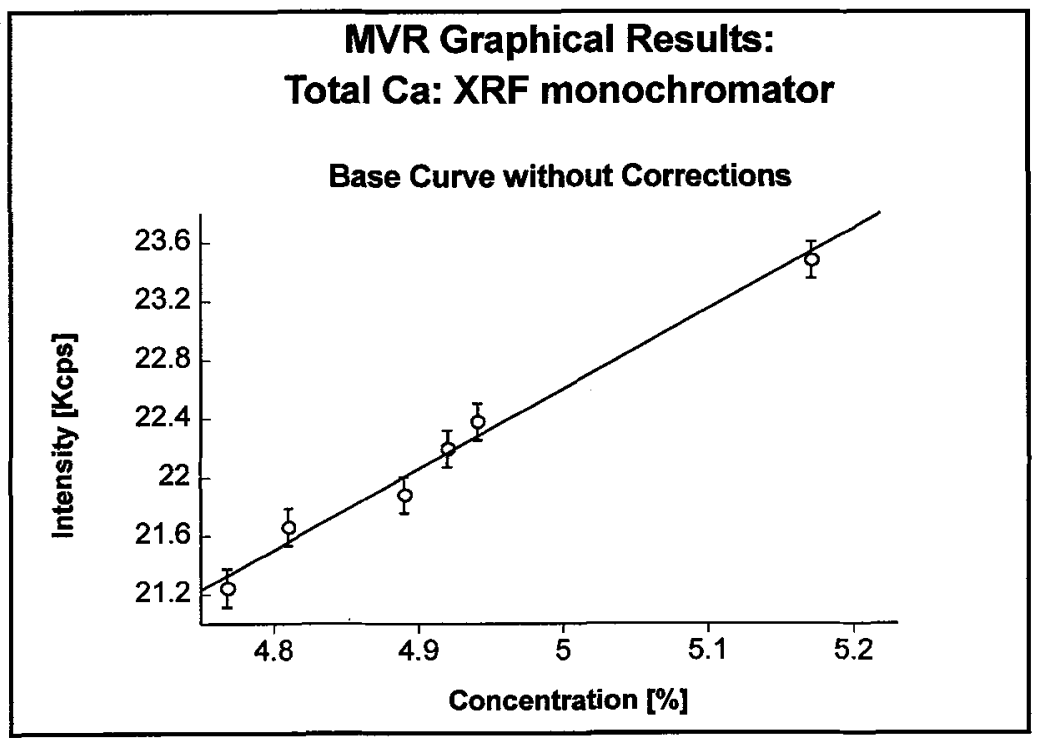


Figure 6: XRD calibration curve for the $\alpha-\mathrm{Al}_{2} \mathrm{O}_{3}$ in a series of alumina samples

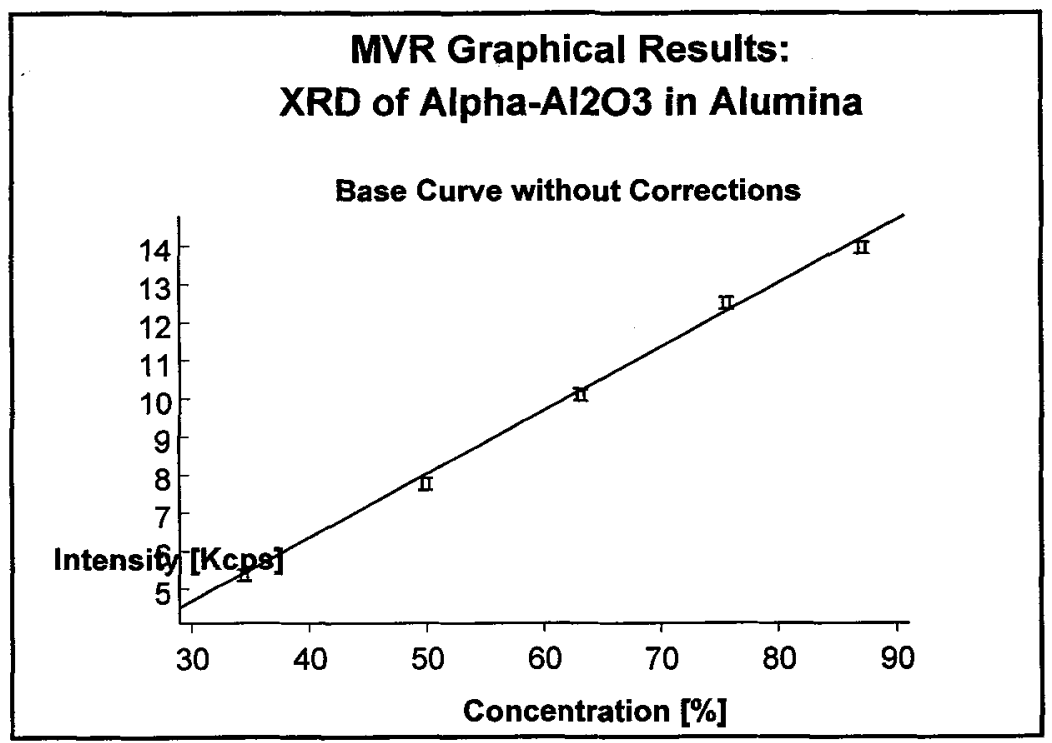

Figure 7: XRD scans on two samples of titanium oxide.

One sample presents an intense rutile peak with very small amounts of anatase while the other shows the opposite situation.

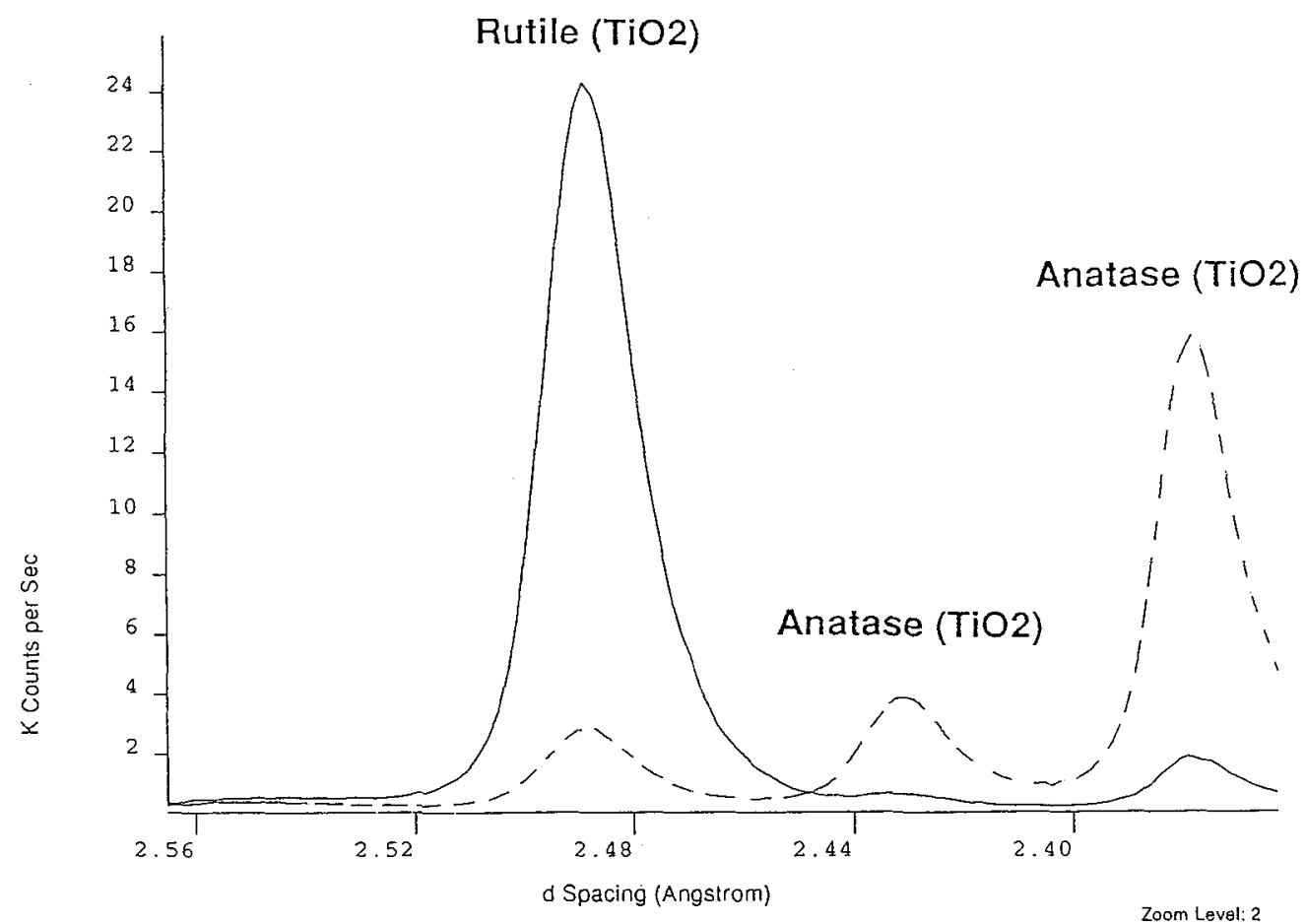


Figure 8: XRD calibration curve for rutile phase in titanium oxides.

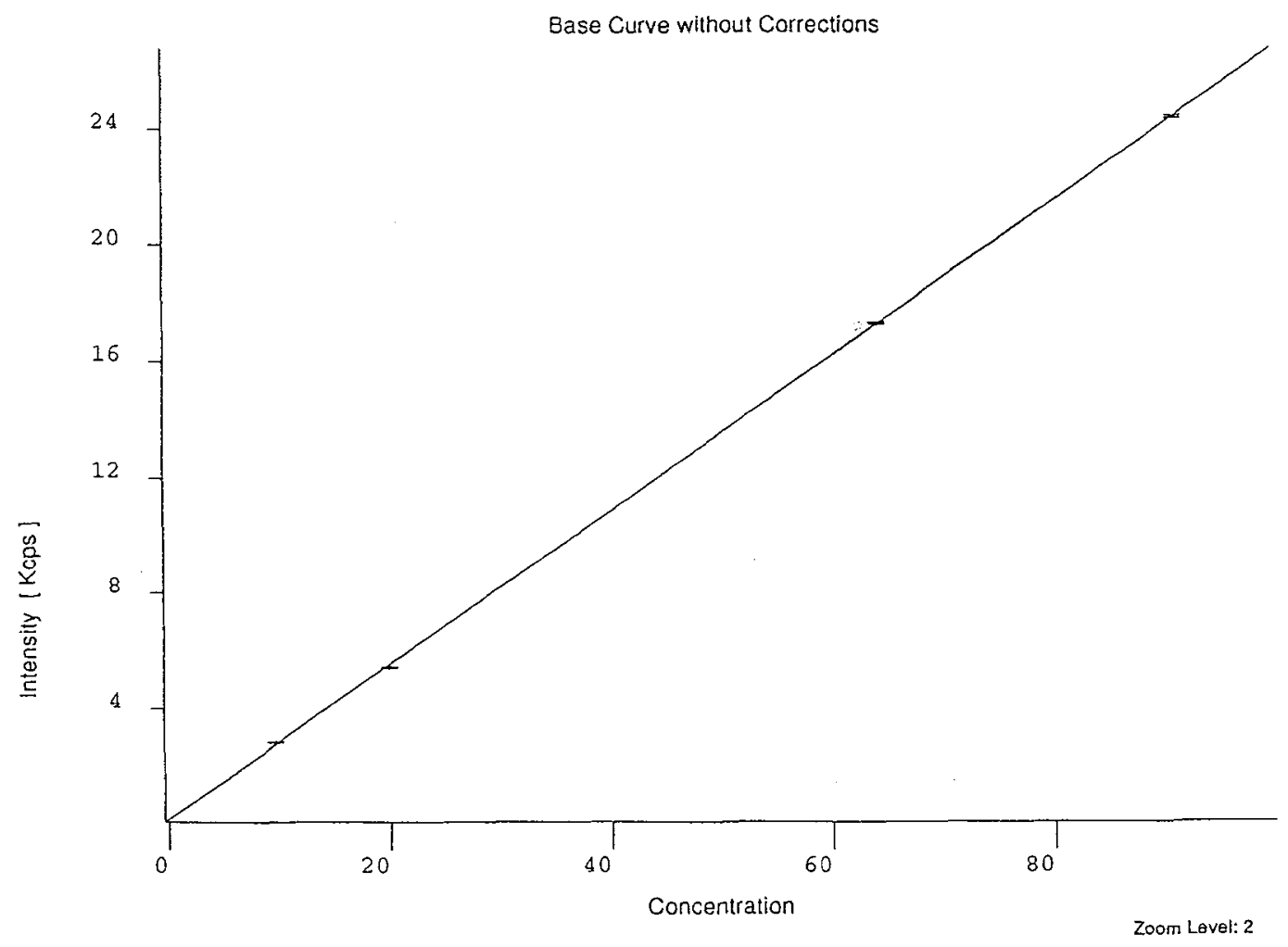

